\title{
MATO, Daniel (Coord.). Educación superior y pueblos indígenas y afrodescendientes en América Latina: normas, políticas y prácticas. Caracas: IESALC-UNESCO, 2012. 364 p.
}

\author{
Maria Simone Jacomini Novak
}

Uma análise das políticas de Ensino Superior em instituições interculturais ou da inclusão da intercultaralidade em instituições convencionais a partir da apresentação de como esse processo vem ocorrendo em oito países da América Latina é o objetivo central do livro organizado por Daniel Mato, professor da Universidade Nacional Três de Fevereiro - UNTREF, Argentina, e coordenador do projeto Diversidade Cultural e Interculturalidade em Educação Superior na América Latina.

No momento em que se consolidam políticas de ação afirmativa e inclusão social em diferentes países, o livro cumpre o importante papel de apresentar um panorama geral acerca de como esse processo vem sendo conduzido na América Latina, uma vez que ainda são poucos os estudos divulgados sobre essa temática, em nível regional e internacional. O livro é a quarta produção com apoio da IESALC-Unesco, e teve como objetivo central documentar, analisar e discutir as experiências de Instituições de Ensino Superior que apresentam políticas específicas para povos indígenas e afrodescendentes.

Para Mato (2012), a permanência das injustiças, a ignorância acerca da importância da diversidade cultural no Ensino Superior e a insuficiência de sua inclusão em programas especiais nas IIESs (Instituições Interculturais de Educação Superior) justificaram o apoio da IESALC-Unesco ao desenvolvimento desse projeto, que desde meados de 2007 realiza as pesquisas cujos resultados são apresentados na obra. Esta é a última de uma série de três publicações sobre a temática. Os livros anteriores mostraram a necessidade de analisar os obstáculos e possibilidades das IIESs, bem como os programas destas instituições a serem estabelecidos, funcionarem e se desenvolverem nos contextos normativos das políticas públicas dos respectivos países. Tendo como objetivo fazer um estudo a partir de casos específicos, a obra contém 364 páginas e é dividida em nove capítulos.

\footnotetext{
* Doutoranda em Educação pela Universidade Estadual de Maringá. Docente da Universidade Estadual do Paraná - Campus Paranavaí (FAFIPA). E-mail: <msimojacomini@hotmail.com>
} 
O primeiro capítulo faz um balanço geral das políticas públicas, leis e práticas institucionais referentes às políticas de Educação Superior para povos indígenas e afrodescendentes na America Latina, a partir de um breve panorama dos contextos constitucionais e legais e das políticas de Educação Superior. Os textos compreendem estudos de caso de oito países: Argentina, Bolívia, Brasil, Equador, Guatemala, México, Nicarágua e Peru, todos de autoria de profissionais indígenas ou afrodescendentes. De forma geral, os capítulos apresentam os dados populacionais e educacionais, a legislação pertinente, experiências e recomendações. Cabe referir que a obra busca mostrar um panorama da questão proposta, tendo, assim, caráter mais descritivo do que analítico.

O primeiro capítulo, intitulado Educação Superior, Povos Indígenas e Afrodescendentes na América Latina: Constituições, Leis, Políticas Públicas e Práticas Institucionais, de autoria de Daniel Mato, organizador da obra, apresenta a discussão atual acerca da temática, mostrando que nas duas últimas décadas as sociedades latino-americanas vêm buscando uma maior democratização, com vistas a superar algumas iniquidades que afetam os povos indígenas e afrodescendentes. $\mathrm{Na}$ análise do autor a educação superior na região ainda exerce um papel muito tímido nesse processo. Mostra que um quadro de mudanças pode ser observado nas constituições, leis e políticas públicas elaboradas a partir da reivindicação dessas populações e suas organizações, articuladas com organizações civis de diversos tipos, organismos e agências de cooperação internacional, mas que essas mudanças são ainda insuficientes para solucionar um problema que, na maioria das vezes, é tratado com indiferença ou naturalização. Para Daniel Mato, a Educação Superior da região apresenta avanços nos aspectos de acesso, permanência e conclusão dos cursos, mas não discute a diversidade cultural e o conhecimento desses povos incluídos nos currículos.

O texto apresenta um panorama geral da situação na América Latina, fazendo uma contextualização histórica sobre a cultura institucional das IESs, que tem como herança as relações históricas da região, marcadas pela colonização e escravidão. $\mathrm{O}$ autor salienta que os movimentos de independência do século XIX e a constituição dos Estados nacionais não mudaram radicalmente o cenário colonial, e

[...] através de suas políticas educativas e culturais desenvolveram imaginários nacionais homogeneizantes, negadores das diferenças, da pluralidade de línguas, saberes, modos de organização social, projetos de vida e futuro, e outros atributos dos povos indígenas e afrodescendentes. (MATO, 2012, p. 23).

As IESs da região têm apenas reproduzido os conhecimentos eurocêntricos.

Uma questão importante tratada pelo autor é a falta de estatísticas sobre essas populações no que se refere aos aspectos demográficos das variáveis sociais 
e econômicas originários da perspectiva de invisibilidade que se tem sobre elas na região, o que, inclusive, dificulta a elaboração de políticas públicas. Embora a América Latina tenha características comuns, as realidades são bem diferentes entre os diversos países, em decorrência não de diferenças atuais de oportunidade, mas de características historicamente acumuladas que afetam setores como a educação, a saúde, o emprego, a habitação, etc. Outro elemento destacado são os convênios e os instrumentos internacionais, abordados como marcos normativos e étnico-políticos que buscam contribuir para a efetivação das reformas, com vista à melhoria de oportunidades e à inclusão.

São apresentados os "[...] contextos constitucionais, leis e políticas de Educação Superior para povos indígenas e afrodescendentes nos diversos países latino-americanos" (MATO, 2012, p. 40), evidenciando que este é um panorama heterogêneo e que demanda pesquisas e estudos específicos. A obra apresenta mais detalhadamente informações sobre os países que compõem o livro, os quais dispõem de estudos particulares e dados mais amplos. Em relação aos demais, restringe-se a comentar os marcos legais. Conclui a abordagem evidenciando que as reformas constitucionais e demais legislações têm pouca repercussão na Educação Superior. Problematiza a questão destacando a necessidade de ações que de fato promovam a diversidade cultural e a interculturalidade.

No segundo capítulo, intitulado Políticas de Educação Superior: Povos Originários e Afrodescendentes na Argentina, escrito por Mirta Fabiana Millán, autora que pertence à comunidade Mapuche Urbana, afirma-se que as mudanças socioculturas ocorridas na América Latina nas últimas décadas levaram a mudanças também na Argentina, tendo os povos originários e afrodescendentes ganhado mais visibilidade a partir de um processo de fortalecimento de suas identidades. O marco legal das mudanças se situa na Constituição de 1994, que reconheceu a existência indígena na Argentina. Com relação aos afrodescendentes, na atualidade vêm se organizando instituições que reivindicam seus direitos, tornando-se cada vez mais visíveis sua presença, suas reivindicações e suas ações. O texto apresenta o sistema educacional argentino ao longo da história e seus marcos normativos como um sistema no qual a construção da idendidade nacional foi baseada em uma política pública hegemônica e de branqueamento da raça que levou ao processo de invisibilidade e silenciamento desses povos. Esse cenário começou a se alterar a partir da década de 1990, quando esses povos passaram a cobrar do Estado seus direitos, levando à formulação e reformulação de leis. No tocante à educação intercultural em nível superior, discute suas implicações, alcances e aspectos propositivos na atualidade, evidenciando que ainda é necessário construir uma educação intercultural para todos, e não apenas para as populações mencionadas. Para isso é necessário que se trabalhe de maneira articulada e interinstitucional com os diversos atores sociais. 
O texto Politicas de Educação para Povos Indígenas, Originários, campesinos e afrodescendentes na Bolivia, escrito por María Eugenia Choque Quispe, da etnia Aymara, discute a educação superior como uma das demandas de maior importância na história dos povos indígenas. A constituição boliviana de 2009 traz como princípio que a educação superior deve ser "intracultural, intercultural e multilingue" e que a luta pela educação indígena é parte do movimento indígena dos séculos XIX e XX, visando aos conhecimentos necessários, sobretudo, para a defesa e manutenção de seus territórios. Para isso o movimento tem clara a necessidade de saber a lingua em que são escritas as leis às quais esses povos estarão subordinados. O texto mostra que o processo histórico de educação destinado a esses povos, marcado pelo colonialimso, não considera seus processos próprios de ensino e aprendizagem. Salienta que as primeiras escolas com um sistema de organização próprio dos povos indígenas e geridas por eles foram duramente reprimidas pelo Estado e apresenta experieêcias de estudos em nível superior, tanto em universidades públicas quanto em instituições privadas, que incorporam um processo descolonizador na educação, mostrando modelos das três universidades indígenas comunitárias interculturais da Bolívia (UNIBOL), denominadas Tupak Katari, Casimiro Huanca e Apiaguaiki Tumpa, criadas em 2008, as quais têm entre seus objetivos viabilizar e reconhecer o conhecimento desses povos; mas observa que esse cenário, considerado promissor para os povos indígenas, ainda não se extende aos afrodescententes.

O quarto capítulo, intitulado As políticas públicas de Educação Superior para Indígenas e Afrodescentendes no Brasil: perspectivas e desafios, foi escrito por Maria das Dores de Oliveira-Pankararu, indígena da etnia Pankararu. A autora mostra que atualmente o Brasil vem passando, por discussões acerca da implementação de políticas de ação afirmativa para populações afrodescendentes e indígenas, que, historicametne, são discriminadas no país, mostrando como esssas políticas vêm ocorrendo no Ensino Superior, a partir de processos de inserção e permanência dessas populações. Afirma que as populações indígenas veem a Educação Superior como possibilidade, entre outras, de ocupar lugares estratégicos para reivindicar seus direitos, pensando sobretudo na demarcação e proteção de suas terras, melhores condições de saúde e uma educação indígena diferenciada. Apresenta estudos recentes sobre a temática e analisa ações referentes a indígenas e afrodescendentes no Ensino Superior tomando como referência a década de 1980, período no qual se processaram a democratização do país e a elaboração e promulgação da atual Constituição, esta ocorrida em 1988. Mesmo com a maior inserção desses grupos no Ensino Superior, afirma não se ter ainda o diálogo intercultural, pois as universidades estariam pautadas pela lógica eurocêntrica. Esta lógica, embora apontada em vários dos textos que compõem a obra, não é discutida e analisada em profundidade. 
A autora menciona também a vinculação entre as desigualdades sociais e econômicas oriundas do modelo econômico vigente. Para as populações indígenas ressalta a criação de licenciaturas interculturais desde 2001. Destaca ainda algumas ações afirmativas para a insercão de estudantes indígenas como discentes regulares de algumas universidades estaduais e federais, bem como as iniciativas de políticas de ação afirmativa que vêm buscando inserir afrodescendentes em instituições públicas de Ensino Superior pelo sistema de cotas.

O quinto capítulo, intitulado Decisões, Omissões e Contradicões: interculturalidade e Políticas Públicas na Educação Superiorno Equador, escrito pelo indígena Luis Fernando Cuji, analisa as políticas públicas mais relevantes do país referentes à Educação Superior, com base nos princípios da interculturalidade e diversidade étnica como elementos de reivindicação das populações indígenas e afrodescendentes com objetivo de transformar a educação monocultural. Apresenta as políticas públicas do país que visam inserir indígenas e afrodescendentes a partir de bolsas de estudos, modalidades especiais e outras ações afirmativas, elencando universidades e programas universitários interculturais. Destaca que as políticas de financimamento destes programas são desenvolvidas por meio de convênios entre empresas, ONGs e organismos multilarais e faz referências aos agentes nelas envolvidos. Traz exemplos de políticas que visam divulgar os conhecimentos dessas populacões à sociedade como um todo, mas ainda esbarram na hierarquização. Faz reflexões sobre as políticas que tentam modificar a estrutura do Ensino Superior convencional e seus limites. Sobre as instituições interculturais de Ensino Superior (IIESs) mostra que estas encontram problemas para se legitimar e se desenvolver apresentando deficiências de infraestrutura e qualidade acadêmica.

O sexto capítulo, denominado Politicas de Ensino Superior e Povos Indígenas (Maya, Garifuna y Xinca) na Guatemala, escrito por Juan Chojoj Mux, pertencente ao povo Maya Kaqchikel, é dividido em cinco partes. Na primeira o autor discute a constituição e outras leis que buscam fortalecer e incluir a interculturalidade nas instituições de Educação Superior no país. Na segunda aborda as iniciativas que vêm impulsionando a inclusão da interculturalidade nesse nível de ensino, e para exemplificar, cita a CODISRA - Comissão Presidencial contra a Discriminação e o Racismo, que atua no país desde 2003, propondo políticas antidiscriminatórias em áreas como educação, saúde, moradia, emprego e meio ambiente. Na terceira parte destaca os avanços da interculturalidade na Educação Superior, ressaltando as ações/iniciativas desenvolvidas no âmbito do Ministério da Educação, da Universidade de São Carlos da Guatemala (USAC) e da Universidade Rafael Landívar (URL). Mostra que outras instituições de Educação Superior têm iniciado processos de inclusão do tema interculturalidade nos conteúdos curriculares de algumas carreiras. $\mathrm{Na}$ quarta parte aborda os programas de 
bolsas de estudos como uma iniciativa que contribui sobremaneira para a permanência dos estudantes na universidade. Do ponto de vista das proposições, apresenta um conjunto de recomendações com ênfase na questão da inclusão da interculturalidade nas IESs como forma de ação, e não apenas como um conjunto de leis, salientando que para tanto é necessário criar possibilidades de maior inserção desses povos nestas instituições.

O sétimo capítulo, escrito por Mindahi Crescencio Bastida Muñoz, intitulado Politicas Públicas das Instituições e Programas Interculturais de Educação Superior no México, mostra que até o século XX as políticas destinadas aos povos nativos do México visavam à integração e assimilação, porém essas começam a se modificar a partir do século XXI. Aborda os marcos legais e as estratégias nacionais para a educação, analisando o âmbito nacional e internacional, e nesse sentido traz a Constituição e leis complementares que estabelecem para o Estado o dever de promover a educação com enfoque intercultural no Ensino Superior. Apresenta as universidades interculturais que se iniciaram no país a partir de 2003 e mostra suas principais características, entre as quais se destacam o componente intercultural, a qualidade, o opção pela formação profissional em dois anos, recursos financeiros iguais dos governos federal e estaduais, incentivo à presença de falantes de línguas nativas e consulta às comunidades nos processos de ingresso. Discute o modelo educativo dessas instituições e sua estrutura curricular, bem como os obstáculos que elas enfrentam, sobretudo os relacionados ao processo de avaliação e acreditação e à forma como acessam os fundos públicos e de fomento. Por fim, traz as estratégias e programas das universidades convencionais, institutos tecnológicos e outras instituições do gênero, em sua forma de relação com os povos e estudantes nativos e afrodescendentes, destacando alguns programas de bolsa de estudo.

O oitavo capítulo, Políticas Interculturais em Instituiçoes de Educação Superior na Nicaragua, escrito por Sandra Davis, da etnia Miskitu, e pelo afrodescendente Marcos Williamson, mostra que, embora haja reconhecimento legal por parte do Estado quanto à diversidade cultural, social e linguística, algumas políticas têm aprofundado as desigualdades e limitado as oportunidades dos povos indígenas e afrodescendentes. Abordam os avanços, limitações e propostas para assegurar a inclusão da interculturalidade nas IESs e salientam que as discussões atuais visam iniciar processos de criação de políticas inclusivas e de reformas nos programas universitários, juntando os saberes endógenos dos povos ao conhecimento científico tradicional. Um importante documento que ainda precisa ser colocado em prática, mas para isso necessita principalmente - mas não só de recursos, é o Plano Estratégico de Educação Superior 2011-2021, elaborado pelo Conselho Nacional de Universidades (CNU), o qual inclui a questão da interculturalidade como um dos seus eixos. Os autores também mostram os obstáculos à institucionalização da interculutralidade nas IESs, as quais estão marcadas, na história do país, por suas características monoétnicas e homoge- 
neizadoras. Concluem o capítulo com algumas propostas que o CNU, as IESs e as IIESs podem utilizar na elaboração de suas políticas e planos de ação.

O último capítulo, escrito por Gavina Córdova Cusihuamán, pertencente à comunidade Quechuahablantes, denomina-se Educação Superior no Perú: Os povos indígenas e afrodescendentes as políticas públicas e institucionais. Esse capítulo aborda a questão da inclusão no Ensino Superior dos afrodescendentes e indígenas e de seus conhecimentos, partindo das leis e políticas governamentais resultantes das reivindicações de setores da sociedade civil e especialmente das populações indígenas, com algumas iniciativas referentes ao direito indígena elaboradas a partir de 2002. Esta legislação reconhece, entre outros direitos, o de uma educação bilíngue. Os autores discutem como na prática vêm se efetivando as normas e políticas governamentais e como estas favorecem ou limitam as possibilidades de acesso das populações afrodescendentes e indígenas e a inclusão da interculturalidade nos conteúdos da Educação Superior. Analisa-se a situação dos Institutos Superiores Pedagógicos (ISPs), que constituem para os indígenas uma importante parte da oferta de Educação Superior denominada não universitária, pois são quase exclusivamente eles que oferecem formação docente em Educação Intercultural Bilíngue. Também abordam o caso dos Institutos Superiores Tecnológicos (ISTs) e as instituições convencionais que têm políticas de inclusão e de ação afirmativa, bem como a situação atual da Universidade Intercultural da Amazônia, trazendo algumas conclusões e orientações para a implementação de uma educação intercultural.

Conforme o exposto, a leitura da obra em seu conjunto de textos mostra um panorama abrangente da inclusão de estudantes indígenas e afrodescendentes no Ensino Superior em diferentes países da América Latina, no qual se destacam os esforços de alguns países em criar insituições adequadas às demandas destes grupos culturais. Esse capítulo revela-se, assim, como uma importante fonte de informações, principalmente levando-se em conta que ainda são incipientes os estudos sobre a temática. O panorama apresentado mostra avanços, mas deixa clara a necessidade de efetivação e implementação dos preceitos legais.

Ressaltamos, não obstante, que a questão da diversidade é abordada sem uma maior relação das questões culturais com as questões sociais e econômicas, por isso cabe encerrar esta resenha com a seguinte fala de Pankararu:

Sabe-se que a exclusão, as desigualdades sociais e econômicas são inerentemente vinculadas ao modelo econômico vigente. Está no cerne do capitalismo a exclusão de uns em benefício de outros, a hegemonia de uma classe dominante em detrimento das classes dominadas, marginalizadas e subvalorizadas, sem o acesso ao saber historicamente produzido pela humanidade e sem acesso aos bens materiais para viver com dignidade. (OLIVEIRA-PANKARARU, 2012, p. 182). 
De forma geral, com excessão, sobretudo, do capítulo da autora acima citada, a questão da interculturalidade não é apresentada a partir dessa vinculação e não se mostra sua historicidade e sua origem europeia, já que a crítica ao eurocentrismo é bastante presente nos diferentes capítulos que compõem a obra.

Ademais, elementos centrais que levaram e levam à expropriação e exclusão dessas populações, como a concentração da renda, a propriedade privada da terra, a destruição ambiental causada pelo sistema capitalista, a exploração e o interese dos organismos internacionais que disseminam essas poíticas -, os quais persistem de foma acentuada nos países da América Latina, apesar das políticas e leis que "protegem" a diversidade, não foram abordados com a devida profundidade que um tema com essa complexidade requer.

\section{Referência}

OLIVEIRA-PANKARARU, M. das D. de. As políticas públicas de Educação Superior para Indígenas e Afrodescentendes no Brasil: Perspectivas e dasafios. In: MATO, D. (Coord.). Educación superior y pueblos indígenas y afrodescendientes en América Latina: normas, políticas y prácticas. Caracas: IESALC-UNESCO, 2012. p. 177-210. 